\title{
Effect Factor Analysis of the Change in Traditional Raiment Culture of the Qiang Nationality
}

\author{
Jia Li ${ }^{1, a}$, Weijue Fan², b \\ ${ }^{1}$ School of Fine Arts \& Design, Hubei University for Nationalities, Enshi 445000, China; \\ ${ }^{2}$ School of Fine Arts \& Design, Hubei University for Nationalities, Enshi 445000, China. \\ alijia628@163.com, bfanweijue@126.com
}

Keywords: Qiang nationality, Raiment culture , Change, Effect factor

\begin{abstract}
Traditional costume is an important carrier of the culture of the Qiang nationality. As Qiang people blossoms in social life, their raiment culture also cannot be isolated from this change with various factors affected. This paper analyses the factors that changes the Qiang raiment culture from the perspective of internal and external causes and concludes that changes in the dress conception and aesthetic sense, religious culture are the internal causes; changes in the living environment, the influence of cultural customs, multi-cultural blending are the external causes.

National costumes are a representation of national identity, which boosts unique and rich cultural connotations. Formed in the long history of development, normal living and production, raiment culture of the Qiang nationality enjoys strong regional and ethnic characteristics. Enriched by historical transformation and the development of society, raiment culture of the Qiang nationality becomes the essence of a traditional ethnic culture and the cultural icon that represents national spirit, and also demonstrates distinctive features of the times and represents of the national spirit. In a sense, the change in traditional raiment culture is a crucial barrier of the historical culture of Qiang nationality, as well as an intangible national encyclopedia. Factors affecting the change of raiment culture of Qiang nationality are miscellaneous. This paper analyses relating factors that changes Qiang raiment culture from the perspective of internal and external causes.
\end{abstract}

\section{Internal causes to the change in traditional Qiang raiment culture}

(1) The influence of religious culture

Religious culture belongs to the category of spiritual culture, and reflects people's psychological needs and way of knowing the world. Religion "is not only a cultural phenomenon, but also a cultural phenomenon with unique form [1]". Although raiment culture belongs to the category of material culture, it also has close links with the religious culture in many ways, both of which are integral parts of ethnic culture. Ethnic raiment culture can reflect religious culture; in the meantime, religious culture can guide and restrict the growth of ethnic raiment culture. In the process of social modernization of Qiang nationality, the two culture of the Qiang nationality have transformed from the original model. The religious culture of the Qiang nationality does not fade in the development, but continues to meet the needs of social modernization and generates some new embodiments in the raiment culture. The influence of religious culture to Qiang's raiment culture mainly reflected in two aspects: the first is the clothing colors, the second is the embroidery of clothing.

Qiang people worship white stone, and white is frequently used in the traditional costume. However, (C) 2016. The authors - Published by Atlantis Press 580 
in recent years, red has become another important color in the traditional costume of Qiang people. For example, in previous time, women in Hei Hu township Mao County wind their heads with long white cloth, and both ends of the cloth hung down to the vest. This way of winding headscarves is known as "million years of filial piety", which was originated from a legend of the General "Black tiger". Women wearing headscarves of this type is for the commemoration of the national hero "Black tiger". And on the special occasion for celebrating the festival "Black tiger Qiang", people replace the white cloth with red cloth in order to cultivate happy and festive atmosphere. Qiang is a nation of polytheism. Qiang embroidery enjoys rich and varied themes. Fire, sheep, cloud, Sun and a variety of flora and fauna in nature are the source of the theme of Qiang embroidery. Ancient embroidery patterns on the dress are the visual manifestation of Qiang people's religious beliefs. As other foreign religion communicates and exchanges with the local religions, Qiang embroidery witnesses a series of changes, for example, "S与", which is from tibetan culture, has also appeared in a number of Qiang embroidery work in recent years. These changes in color and decorative pattern are formed under the influence of the religious culture of different peoples.

\section{(2) Changes in the dress conception}

Only if individuals or groups inherit and develop their culture in the way of language, words, behavior, can the culture exist and continue to grow. Since behavior is dominated by personal consciousness, and costume is a typical manifestation of personal behavior, the dress conception is the most direct internal cause of dressing behavior. The style of costume varies, so does the dress conception. The cause for the fundamental difference among dressing conceptions lies in people's recognition to the function of the costume. The costume of people mainly has three functions: first, practical function, which refers to meet the need of people in their daily life, is for body protection, cold resistance and heat shielding; second, aesthetics function, which reflects people's aesthetic sense, is for decorative purpose; third, the function of identification, which identifies the difference with respect to social function, is to reflect social connotations, such as gender, age, nationality, career, religion, and social status. Different dress conceptions have different influence on the function of costume.

Different functions determine the differences in dressing forms in selection of clothes, the choice of functions being one aspect of dressing concepts. So the change in dressing concepts may bring about change in choosing clothes. The transition of the costume culture of Qiang people also corresponds to the change of concepts in their national costume culture. Formerly Qiang people inhabited in the remote mountain districts with poor living conditions and deficient physical resources. When choosing clothes, more attentions were paid on practicability and durability, because the dressing should accord with daily life and production; and wear-resisting clothes would reduce unnecessary waste. For Qiang people in the past, the main functions of costumes, which are also the basic ones, were embodied in covering the body and defending against the cold. In the old days, Qiang people usually wore sheepskin waistcoats (see fig.1) when working. Its function was not confined to keeping out wind and rain; it was also a cushion at break time when being tuned outside in. At present sheepskin waistcoats are rarely seen in their inhabited regions, and the craftsmanship has been endangered. Qiang people take it as a normal way of dressing, a way decided by their traditional view, for women to wear scarves, unlined long gowns, waistcoats and girdles and for men to wear Yun Yun shoes with Gu Du wrapped on the waist. However, with the development of society and improvement of living conditions, their dressing concept also alters. They

gradually realize that the functions of clothes were not merely limited to covering the body and keeping it warm, but more a reflection of the individual aesthetic taste. The ideological emancipation gives rise to changes in actions, and the diversification of dressing is among them.

\section{(3)The Changes in Aesthetic Taste}

As the external expression of beauty, the evolution of clothes was certainly under the influence of men's 
aesthetic taste. The costumes of Qiang people being the direct expression of their aesthetic taste, when people change in aesthetic standards, their choice of costumes change. As the society and economy progress, men's demands for clothes step up to a pursuit of beauty. Beautiful and elegant dressing is the most direct sensory reflection of people's visual sense. The subjective feelings of beauty and ugliness are expressed in exterior forms of clothes such as matching, style, color, texture and clipping. People's difference judgment criteria of the beauty and ugliness of clothes make them match and select clothes variously.

The transition of costume culture of Qiang people is also influenced by their aesthetic ideas. In term of design, clothes changed from the original long gown, waistcoat, Yun Yun shoes, to the modern short sleeve, jeans and leather shoes, not only influenced by social progress, but restricted by the collective aesthetic taste of people. Advocating white, Qiang people wear scarves, long gowns, Yun Yun shoes, the main color of which is white. The social development and the scientific improvement also bring about the changes in texture and color of shell fabric.

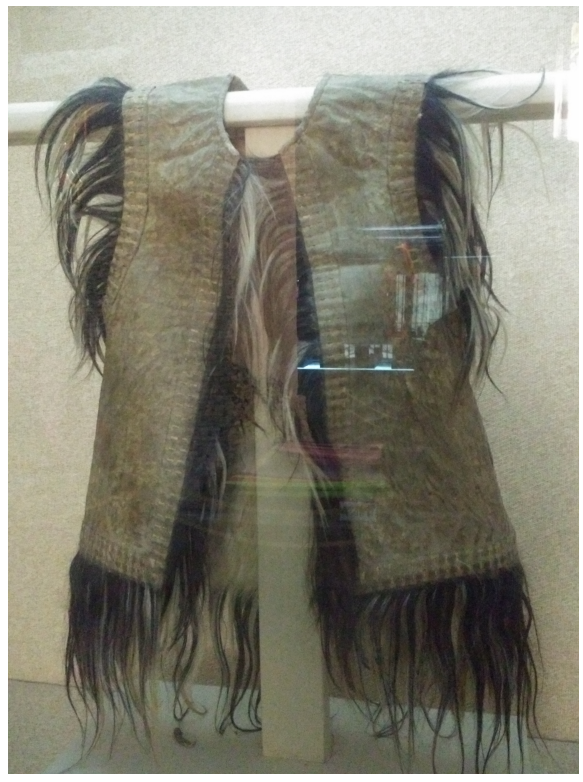

Fig.1 Sheepskin waistcoat Shot by the author

\section{The external cause of the transition of Qiang costume culture}

\section{(1) The restriction of living conditions}

In the long history of people's making efforts to adapt to the nature and then transform it and meanwhile create a splendid culture, costume culture emerged through the adaptive selection. The formation and evolution of costume culture is closely related to the natural environment where people live. It is easy to learn from the evolution of Qiang costume culture that it has been restricted by the living conditions to some extent.

The early Qiangs were nomadic people, and puttee evolved from nomadic costumes. Now only some older Qiangs keep the puttee custom, while generally young people do not. It is relatively common for women of alpine regions to use puttee, firstly to protect against moisture and keep warm, secondly to prevent the legs from being hurt by snakes, insects, thistles and thorns as well as rocks. As the west part of Li County and the south part of Mao County were near Tibetan inhabited regions, their costume culture shows a characteristic of being influenced by that of Tibetans. As Mianhu Town of Wenchuan is close to the 213 national road, with a comparatively advantaged geographic position, the choice of clothes is relatively varied. Qiang people of Heihu Village of Mao County, however, as they live in mountainous areas, with inaccessible communications, hard living conditions and scarce resources, they have much 
less choices in clothes than Qiangs of Mianhu Town. The emergence of clothes is an adaptive strategy of humans in living in the nature, and also a result of interaction between men and natural environment. Different environments bring about the differences in selecting clothes of Qiang people in various areas, which are caused by men's adaption to the environment. So the transition of costume culture is influenced by living environments.

\section{(2)The influence of social ethos}

Social ethos includes many aspects, such as constraints from politics and policy, the influence of economic development and the guidance of fashion trends. Since the 20th century, Chinese society has undergone several major changes in the political, economic and social structures, which has brought great changes to the clothing culture and as a result, the Qiang clothing culture has also been affected to a certain extent.

On the one hand, the Qiang traditional clothing is a product of natural economy, arising from and maturing in the specific historical and cultural background. With the development of productivity, especially after entering into the industrialized society, the manual production has been gradually replaced by machine production since the cost of the machine production is far below the hand-made. This change has inevitably left great impacts on the development of ethnic traditional clothes[2]. The "Machine Fun" of machine production is far different from the "Aesthetic Charm" of manual production. The Qiang clothing culture is mostly influenced by the changes in ways of materials production, and with social development and the gradual improvement of the public's purchasing power, the tools and raw materials of making have also been considerably changed. On the other hand, the trend of the times has also exerted significant influence over the changes of the clothing culture.

The clothing culture, as a part of the national culture, in the period of social and political reforms, can easily become an object which should be "reformed" and lead to changes in the clothing style. During the Republic of China, western culture was introduced into China, and as a result, the Qiang clothing culture was also influenced by Western trends and a lot of people were wearing Chinese tunic suits, leather shoes and western jewelries, etc. The western clothing ideology advocating nature and health, focusing on the beauty of the human body and some other ideas, have gradually been integrated into the Chinese people's dressing behaviors, bringing greater changes to the domestic clothing culture. Since the reform and opening up, China's clothing culture has entered into a period of prosperity, and Qiang clothing culture has also developed into a diversified and personalized era. For example, the traditional long gown is slowly being replaced by Chinese tunic suit and workwear, and leg wrappings are slowly disappearing. As the reform and opening up is driving the economic and social development, the Qiang clothing culture has also been changed due to the changes of social ethos.

\section{(3)The infiltration of foreign culture}

Exchanges between national culture and foreign culture, is an important factor to promote dressing changes. Throughout the history of human clothing culture, the formation of the modern clothing culture is just the outcome of cultural exchanges, infiltration and integration between different nations. In the process of ethnic development, the Qiang clothing culture has been influenced by the clothing culture of other nationalities, including the Tibetan, Han, Yi and others. Constantly absorbing elements from exotic clothing cultures, the Qiang clothing culture has gradually evolved into such a unique clothing culture.

Most people from Qiang ethnic group live in remote mountainous areas. Before the reform and opening up, because of the poor transportation and being in a closed natural economy for a long time, Qiang group was relatively little affected by modern civilization and foreign cultures. Such an environment is unfavorable to the economic development of Qiang, but actually beneficial to the protection and inheritance of Qiang culture. 


\section{Summary}

After the reform and opening up, with the improvement of traffic conditions and economic and cultural development, Qiang group has been increasingly making cultural exchanges with other neighboring peoples, which to a certain extent has also influenced the clothing culture, causing changes in clothing styles and embroidery patterns, and these changes are the product of cultural exchanges and integration. Thus it can be seen that there are reasons for the changes in the Qiang clothing culture, which also gives us a lot of revelations. First, changes in the Qiang traditional clothing is absolute but the stability is relative. Second, the transition patterns of the Qiang clothing culture should be analyzed and summarized, which is of great guiding significance for the discovery, protection and development of current minority culture. Third, the infiltration of new cultural elements and cultural characteristics is the root cause of the Qiang clothing changes, which has not led to the loss of cultural identity, but enriched the connotation of the Qiang clothing culture.

\section{References}

[1] Zhang Yudong: Reflections on the relationship between religion and culture. Journal of Huaqiao University (Philosophy Edition), 1999 (1).

[2] Huang Boquan: Contemporary changes of traditional ethnic clothing. Journal of Southwest University for Nationalities (Humanities and Social Sciences), 2011 (1). 